\title{
PERBANDINGAN KADAR NIPAGIN PADA KECAP MIE INSTAN DAN KECAP BOTOLAN YANG DIPERJUALBELIKAN DI KOTA MAKASSAR
}

\section{COMPARISON OF NIPAGIN CONSIDERATIONS IN INSTANT MIE KITCHEN AND COCONUT BOTTLEED IN MAKASSAR CITY}

\author{
Rahmawati ${ }^{1)}$, Anita $^{2)}$, Rezky Marwah Ulfa ${ }^{3)}$ \\ ${ }^{123)}$ Teknologi Laboratorium Medis Politeknik Kesehatan Muhammadiyah Makassar
}

Koresponden: rahmawatiamma60@gmail.com

\begin{abstract}
Nipagin is a preservative that is allowed to use in food, but the levels should not exceed the maximum limit set by Permenkes RI No. 722 / Menkes / Per / IX /1988 about food additives that is $250 \mathrm{mg} / \mathrm{kg}$. The purpose of this study was to determine the nipagin levels contained in instant mie kitchen and coconut bottleed in Makassar city using spectrophotometer uv-vis method using deniges and sodium nitrite $2 \%$ reagent. The results showed that the results of nipagin levels ratio in instant mie kitchen and coconut bottleed by UV-VIS spectrophotometer,instant mie kitchen (1) were obtained at 0.0105 $\mathrm{mg} / \mathrm{g}$, (2) $0.0135 \mathrm{mg} / \mathrm{g}$, (3) $0.0108 \mathrm{mg} / \mathrm{g}$, (4) $0.012 \mathrm{mg} / \mathrm{g}$, (5) $0.0073 \mathrm{mg} / \mathrm{g}$, (6) 0.0182 $\mathrm{mg} / \mathrm{g}$, (7) ) $0.0079 \mathrm{mg} / \mathrm{g}$, (8) $0.01 \mathrm{mg} / \mathrm{g}$, (9) $0.0071 \mathrm{mg} / \mathrm{g}$, (10) $0.0152 \mathrm{mg} / \mathrm{g}$. Positive contains nipagin when the color change becomes pink. The pink color formed measured its absorbance at a wavelength of $504 \mathrm{~nm}$. The calibration curve was made in concentrations of $0,15,20,22,25$, and $30 \mathrm{mg} / \mathrm{ml}$ and obtained the regression equation $Y=0.0022 x-0.0017$. The result of data analysis using $t$-test obtained $p=0,73>0,05$ meaning Ho accepted and Ha rejected, while result of manual analysis obtained by $t$ count $(-0,3706)<t$ table (2,262), so it can be concluded that There was no significant difference between nipagin levels of instant noodle soy sauce and bottled soy sauce.
\end{abstract}

Keywords: soy sauce, preservative, nipagin, spectrophotometer uv-vis

\begin{abstract}
ABSTRAK
Nipagin merupakan bahan pengawet yang diizinkan penggunaannya dalam makanan, tetapi kadarnya tidak boleh melebihi batas maksimum yang ditetapkan oleh Permenkes RI No. 722/Menkes/Per/IX/ 1988 tentang bahan tambahan makanan yaitu $250 \mathrm{mg} / \mathrm{kg}$. Tujuan dari penelitian ini adalah untuk menentukan kadar nipagin yang terdapat dalam kecap mie instan dan kecap botolan yang diperjualbelikan di kota Makassar dengan metode spektrofotometer UV-VIS menggunakan pereaksi deniges dan natrium nitrit $2 \%$. Hasil penelitan menunjukkan bahwa diperoleh hasil kadar nipagin pada kecap mie instan dan kecap botolan secara spektrofotometer UV-VIS , kecap mie (1) di dapatkan kadar nipagin 0,0105 mg/g, kecap mie (2) $0,0135 \mathrm{mg} / \mathrm{g}$, kecap mie (3) 0,0108 mg/g, kecap mie (4) 0,012 mg/g, kecap mie (5) $0,0073 \mathrm{mg} / \mathrm{g}$, kecap botolan (6) 0,0182 mg/g, kecap botolan (7) 0,0079 mg/g, kecap botolan (8) 0,01 mg/g, kecap botolan (9) 0,0071 $\mathrm{mg} / \mathrm{g}$, kecap botolan (10) $0,0152 \mathrm{mg} / \mathrm{g}$. Positif mengandung nipagin apabila perubahan warna menjadi merah muda. Warna merah muda yang terbentuk diukur absorbansinya pada panjang gelombang $504 \mathrm{~nm}$. Kurva kalibrasi dibuat dalam konsentrasi 0, 15, 20, 22 , 25, dan $30 \mathrm{mg} / \mathrm{ml}$ dan diperoleh persamaan regresi y $=0,0022 \mathrm{x}-0,0017$. Hasil
\end{abstract}


analisa data dengan menggunakan uji-t diperoleh $\mathrm{p}=0,73>0,05$ artinya Ho diterima dan Ha ditolak, sedangkan hasil analisa manual diperoleh hasil t-hitung $(-0,3706)<\mathrm{t}$ tabel $(2,262)$, sehingga dapat disimpulkan bahwa tidak ada perbedaan yang signifikan antara kadar nipagin kecap mie instan dan kecap botolan.

Kata kunci: kecap, pengawet, nipagin, spektrofotometer uv-vis

\section{PENDAHULUAN}

Bahan tambahan pangan (BTP) dalam peraturan menteri kesehatan RI No.772/Menkes/Per/IX/ 1988 secara umum adalah bahan yang biasanya tidak digunakan sebagai makanan dan biasanya bukan merupakan komponen khas makanan, mempunyai atau tidak mempunyai nilai gizi, yang dengan sengaja ditambahkan ke dalam makanan untuk maksud teknologi pada pembuatan, pengolahan, penyiapan, perlakuan, pengemasan, dan penyimpanan (Purwiyatno dan Ratih, 2009).

Bahan pengawet adalah senyawa yang mampu menghambat dan menghentikan proses fermentasi, pengasaman, atau bentuk kerusakan lainnya, atau bahan yang dapat memberikan perlindungan bahan pangan dari pembusukan. Menurut Peraturan Menteri Kesehatan Republik Indonesia Nomor 722/Menkes/Per/IX/1988 tentang bahan tambahan pangan yang mencegah atau menghambat fermentasi, pengasaman, atau peruraian lain terhadap pangan yang disebabkan oleh mikroorganisme. Meskipun demikian, penggunaan bahan pengawet memiliki tujuan yang sama, yaitu mempertahankan kualitas dan memperpanjang umur simpan bahan pangan (Cahyadi, 2008).

Nipagin yang disebut juga sebagai metil paraben termasuk dalam bahan pengawet makanan khususnya anti jamur yang juga digunakan secara luas sebagai pengawet untuk obat-obatan dan kosmetika. Menurut Badan Pengawas Obat dan Makanan (BPOM), penggunaan nipagin di Indonesia diatur dalam Permenkes RI No 722/Menkes/Per/IX/1988 tentang bahan tambahan makanan yang mengizinkan penggunaan nipagin dalam kecap dengan batas maksimum $250 \mathrm{mg} / \mathrm{kg}$ (Standar Nasional Indonesia, 1999).

Mi instan merupakan makanan yang sangat populer, digemari berbagai kalangan dan berpotensi sebagai salah satu makanan alternatif pengganti beras. Hal ini disebabkan karena mi instan memiliki rasa yang enak, proses penyajian yang mudah dan cepat, jumlah kalori cukup tinggi, harga relatif murah dan dapat diproduksi dalam berbagai bentuk yang menarik serta daya simpan yang baik. Karena memiliki daya simpan yang baik, mi instan sering dipertanyakan apakah menggunakan bahan kimia sebagai pengawet dalam proses pembuatannya. Setiap bungkus mie instan terdapat satu sachet bumbu dan beberapa bahan-bahan lainnya, seperti flavouring, kecap, saos, dan solid ingredient seperti sosis, suwiran sayur, bawang goreng, cabe kering dan sebagainya (Anonim, 2011).

Pada proses pembuatan mi, pengawetan dilakukan dengan deep frying yaitu penggorengan dalam minyak goreng panas pada suhu 1200$1600^{\circ} \mathrm{C}$ selama \pm 2 menit sampai kering dan diperoleh kadar air kurang dari $4 \%$ sehingga mikroorganisme tidak dapat berkembang biak (Eep, 2006). Sedangkan pembuatan bumbubumbunya menggunakan bahan kimia sebagai pengawet. Pengawet yang paling umum digunakan yaitu asam benzoat dan nipagin (Chu, Chen, dan Wang, 2003). 
Kecap mie instan adalah produk olahan/awetan kedelai dengan tekstur cair (asin) atau kental (manis). berwarna cokelat kehitam-hitaman, dan digunakan sebagai bahan pelengkap makanan. Kecap botolan adalah cairan hasil fermentasi bahan nabati atau hewani berprotein tinggi di dalam larutan garam. Kecap berwarna coklat tua, berbau khas, rasa asin dan dapat menyedapkan rasa masakan (Suprapti, 2005).

Kecap, chili sauce, dan tomato sauce adalah adalah bahan makanan yang sering dijumpai di pasaran dan sangat diminati oleh masyarakat untuk dikonsumsi dalam kehidupan seharihari. Bahan makanan ini menggunakan bahan pengawet. Banyak jenis pengawet yang digunakan untuk mengawetkan bahan pangan. Salah satu bahan pengawet yang sering dipakai pada kecap adalah metil p-hidroksi benzoate (nipagin). Nipagin juga sering digunakan untuk mengawetkan sari buah, minuman ringan, saus, selai, jeli, manisan, dan lain-lain (Cahyadi, 2008).

Penggunaan pengawet kimia seperti nipagin banyak digunakan di Indonesia. Hal ini disebabkan karena daya mengawetkan makanan dari zat ini sangat baik. Namun penggunaannya sering melewati batas maksimum yang dipersyaratkan dalam Permenkes no.722/1988. Penetapan kadar metil paraben dalam kecap dan saus dapat dilakukan dengan berbagai metode. Menurut beberapa literatur dapat ditentukan antara lain dengan metode spektrofotometri UV-VIS, Kromatografi Lapis Tipis (SNI, 1992).

Berdasarkan uraian di atas, dilakukan penelitian untuk mengetahui Perbandingan Kadar Nipagin pada Kecap Mie Instan dan Kecap Botolan yang diperjualbelikan di Kota Makassar dengan menggunakan metode Spektrofotometer UV-VIS.

\section{METODE}

\section{Lokasi Penelitian}

Penelitian dilaksanakan di Laboratorium Kimia Fakultas Saintek Universitas Islam Negeri Alauddin Makassar

\section{Populasi dan Sampel}

Populasi dalam penelitian ini adalah semua jenis kecap dan sampel dalam penelitian ini adalah kecap mie instan, yaitu kecap mie goreng bawang, mie goreng indomie, mie intermie, mie sarimi, dan mie sedap sedangkan kecap botolan yaitu kecap saori, ABC, sedap, bango, dan asin .

\section{Teknik Pengambilan Sampel}

Teknik pengambilan sampel yang digunakan yaitu simple random sampling. Menurut Sugiyono (2001) teknik simple random sampling atau teknik acak sederhana adalah teknik pengambilan sampel dari anggota populasi yang dilakukan secara acak tanpa memperhatikan strata yang ada dalam populasi itu, sehingga anggota populasi memiliki kesempatan yang sama untuk terpiih menjadi sampel.

\section{Alat dan Bahan}

Alat yang digunakan adalah beaker glass, pipet tetes, labu ukur, batang pengaduk, pipet volum, cawan porselin, timbangan, pulp, tabung reaksi, rak tabung, pembakar spiritus.

Bahan yang digunakan adalah sampel (kecap mie instan dan kecap botolan), dietil eter, pereaksi deniges, $\mathrm{NaNO}_{2} 2 \%$, standar nipagin.

\section{Prosedur Kerja}

a. Pembuatan larutan pereaksi

1) Pembuatan larutan deniges (Siallagaan, E., 2011)

5 gram $\mathrm{HgO}$ dilarutkan dalam 40 $\mathrm{ml}$ dan ditambahkan $20 \mathrm{ml}$ $\mathrm{H}_{2} \mathrm{SO}_{4} \quad 100 \mathrm{ml}$, kemudian ditambahkan kembali $40 \mathrm{ml} \mathrm{H}_{2} \mathrm{O}$.

2) Pembuatan laruran $\mathrm{NaNO}_{2} 2 \%$ (Ditjen POM, 1995) 
Ditimbang 2 gr $\quad \mathrm{NaNO}_{2}$, kemudian dimasukkan kedalam labu ukur $100 \mathrm{ml}$, dicukupkan volume sampai batas $100 \mathrm{ml}$.

b. Analisa Kualitatif Sampel (Egan, Kirk, dan Sawyer, 1981)

Sampel yang diperiksa dalam penelitian ini adalah kecap yang terdapat dalam mie instan dan kecap botolan sebanyak 2 g. Sampel tersebut diekstraksi dalam gelas kimia menggunakan dietil eter sebanyak $5 \mathrm{ml}$, kemudian diasamkan dengan $\mathrm{HCl}$ sampai $\mathrm{pH} 1$. Selanjutnya diambil lapisan dietil eter kemudian diuapkan dan ditambahkan $0,5 \mathrm{ml}$ pereaksi deniges lalu dipanaskan, kemudian ditambahkan $0,5 \mathrm{ml}$ pereaksi $\mathrm{NaNO}_{2}$ $2 \%$. Sampel didiamkan selama 42 menit, perubahan warna menjadi warna merah muda, berarti postif mengandung nipagin.

c. Analisa Kuantitatif Sampel (Egan, Kirk, dan Sawyer, 1981)

1) Pembuatan Larutan Standar Nipagin

Larutan standar nipagin dibuat dalam 100 ppm dengan menimbang nipagin $0,1 \mathrm{mg}$ kemudian dilarutkan dengan sedikit alcohol $96 \%$. Kemudian dihimpitkan dengan akuades sampai volume $100 \mathrm{ml}$. setelah itu, dibuat deret standar dengan konsentrasi 0 ppm, 15 ppm, 20 ppm, 25 ppm, dan 30 ppm.

2) Pembuatan Kurva Kalibrasi

Kurva kalibrasi dibuat dalam konsentrasi 0, 15, 20, 22, 25, 30 $\mathrm{mg} / \mathrm{L}$. Setelah itu dioptimalkan spektrofotometer sesuai petunjuk penggunaan alat, sehingga diperoleh persamaan regresi. Dari persamaan regresi diperoleh adanya hubungan yang linear antara konsentrasi dan absorbansi.
3) Pengujian Sampel

Setelah dilakukan destilasi terhadap sampel, kandungan nipagin pada larutan tersebut diukur absorbans pada spektrofotometer UV-VIS.

\section{Interpretasi Hasil}

Jika terjadi perubahan warna menjadi merah muda (+) positif mengandung nipagin, sedangkan jika tidak terjadi perubahan warna merah muda maka (-) tidak mengandung nipagin.

\section{Analisis Data}

Data yang diperoleh dianalisis dengan menggunakan uji statistic SPSS ( Uji T dua sampel bebas) (Stang, 2014).

\section{HASIL}

Penelitian telah dilakukan di Laboratorium Kimia Fakultas Sains dan Tekhnologi Universitas Islam Negeri Makassar dengan jumlah sampel yang diperiksa sebanyak 10 sampel kecap diambil secara acak yang diperoleh di supermarket Kota Makassar.

Hasil penelitan menunjukkan bahwa kadar nipagin pada kecap mie instan dengan kode sampel 1, 2, 3, 4, 5 didapatkan masing-masing kadar nipagin $0,0105 \mathrm{mg} / \mathrm{g}, \quad 0,0135 \mathrm{mg} / \mathrm{g}$, $0,0108 \mathrm{mg} / \mathrm{g}, 0,0120 \mathrm{mg} / \mathrm{g}$, dan 0,0075 $\mathrm{mg} / \mathrm{g}$. Sedangkan pada kecap botolan dengan kode sampel $6,7,8,9,10$ didapatkan masing-masing kadar nipagin $0,0182 \mathrm{mg} / \mathrm{g}, \quad 0,0079 \mathrm{mg} / \mathrm{g}$, $0,0100 \mathrm{mg} / \mathrm{g}, 0,0071 \mathrm{mg} / \mathrm{g}$, dan 0,0152 $\mathrm{mg} / \mathrm{g}$.

\section{PEMBAHASAN}

Dalam perbandingan kadar nipagin ini sampel yang digunakan adalah kecap mie instan dan kecap botolan yang diperjualbelikan di Kota Makassar.

Penelitian ini bersifat observasi laboratorik yang bersifat deskriptif. Dimana peneliti melakukan suatu 
analisis kadar nipagin pada kecap mie instan dan kecap botolan.

Pada produk masing-masing sampel kecap yang dianalisis secara kualitatif menunjukkan bahwa sampel tersebut mengandung bahan pengawet nipagin. Oleh karena sampel sampel langsung dianalisis secara kuantitatif dengan menggunakan alat spektrofotometer UV-VIS untuk mengetahui seberapa besar kadar pengawet nipagin yang terdapat dalam masing-masing sampel tersebut.

Penentuan nilai absorbansi pada enam deret larutan standar, yang selanjutnya digunakan sebagai kurva standar. Dari kurva standar antara absorbansi terhadap konsentrasi diperoleh persamaan garis linier yang merupakan hubungan antara absorbansi (y) dengan konsentrasi (x) larutan standar sebagai berikut: $\mathrm{y}=0,0022 \mathrm{x}$ 0,0017 dengan harga $r$ sebesar 0.9904 . Hal ini menyatakan bahwa kurva kalibrasi memiliki keakuratan dalam penentuan konsentrasi sebesar $99 \%$.

Penentuan kadar pengawet nipagin dalam sampel dilakukan pengukuran absorbansi larutan sampel yang merupakan hasil ekstraksi. Konsentrasi (x) nipagin dalam sampel diperoleh dengan cara mensubstitusikan nilai absorbansi larutan sampel terhadap (y) pada persamaan $\mathrm{y}=0,0022 \mathrm{x}$ 0,0017. Kemudian dilakukan perhitungan kadar pengawet nipagin per gram sampel.

Hasil penelitan menunjukkan bahwa tidak satupun dari sampel yang diuji mengandung nipagin yang melebihi batas maksimum yang ditetapkan oleh Permenkes RI No. 722/Menkes/Per/IX/1988 tentang bahan tambahan makanan yaitu $250.000 \mathrm{mg} / \mathrm{g}$. Dengan demikian ke 10 sampel tersebut aman untuk dikonsumsi.

Tujuan penggunaan zat pengawet nipagin dalam produk kecap adalah untuk mencegah pertumbuhan khamir dan bakteri terutama untuk makanan yang telah dibuka dari kemasan.

Dari data hasil penelitian telah dilakukan uji $\mathrm{t}$ uji sampel bebas menggunakan program SPSS. Pengambilan keputusan dalam analisis uji t dapat dilakukan dengan dua cara, analisa data menggunakan SPSS dilakukan dengan cara membandingkan nilai p. dari data yang dihitung, diperoleh hasil p 0,73>0,05 artinya Ho diterima dan Ha ditolak, sedangkan analisa data manual diperoleh hasil t-hitung ($0,3706)<\mathrm{t}$-tabel $(2,262)$, sehingga dapat disimpulkan bahwa tidak ada perbedaan yang signifikan antara kadar nipagin kecap mie instan dan kecap botolan.

\section{KESIMPULAN}

Berdasarkan hasil penelitian yang telah dilakukan, maka dapat disimpulkan bahwa:

1. Semua sampel yang diperiksa mengandung nipagin dengan kadar tidak melebihi ambang batas maksimum yang ditetapkan oleh Permenkes RI No. 722/Menkes/Per/IX/1988, sehingga aman untuk dikonsumsi oleh masyarakat.

2. Data hasil uji t dua sampel bebas diperoleh nilai $p=0,73>0,05$ yaitu Ho diterima dan $\mathrm{Ha}$ ditolak, sedangkan analisis data manual diperoleh hasil t- hitung $(-0,3706)<$ t-tabel (2,262), berarti tidak ada perbedaan yang signifikan antara kadar nipagin pada kecap mie instan dan kecap botolan.

\section{DAFTAR PUSTAKA}

Anonim. 2011. Sejarah Kecap. http:// http://www.scribd.com/doc/4467 5202/pappertekfer [12 Mei 2011].

Cahyadi, W. 2008. Analisis Dan Aspek Kesehatan Bahan Tambahan 
Pangan. Bumi Aksara. Jakarta.

Chu, T.Y., Chen, C.L., dan Wang, H.F. 2003. A Rapid Method for The Simultaneous Determination of Preservatives in Soy Sauce. Journal of Food and Drug Analysis. 11 (3): Hal. 246-250.

Ditjen POM. 1995. Farmakope Indonesia. Edisi IV. Jakarta: Departemen Kesehatan RI. Hal. $551,1061,1085$.

Eep. 2006. Mi Instan Sehat, Aman Serta

Layak Dikonsumsi? http://www.Eepinside.com.

Diakses tanggal 28 Februari 2019.

Egan, H., Kirk, R.S., dan Sawyer R. 1981. Pearson's Chemical Analysis of Foods. Eight Edition. London: Longman Scientific \& Technical. Hal. 74- 75.

Purwiyatno, H., dan Ratih, D., 2009. Memproduksi Pangan yang Aman. Jakarta: Dian Rakyat.
[SNI] Standar Nasional Indonesia. 1999. Bahan Tambahan Makanan. Jakarta: Dewan Standarisasi Nasional.

Siallagan, 2011. Penetapan Kadar Nipagin Pada Kecap Mi Instan Secara Spektrofotometri Sinar Tampak. Skripsi Tidak Diterbitkan. Fakultas Farmasi, Universitas Sumatera Utara. Medan

Stang. 2014. Cara Praktis: Penentuan Uji Statistik dalam Penelitian Kesehatan dan Kedokteran. Jakarta: Mitra Wacana Media. Pp: 1-11.

Sugiyono, 2001. Metode Penelitian, Bandung: CV Alfa Beta.

Suprapti, M. L., 2005. Kecap Tradisional. Kanisus, Yogyakarta. 
Tabel 1. Data Hasil Absorbansi Larutan Standar Nipagin

\begin{tabular}{ccc}
\hline No & $\begin{array}{c}\text { Larutan standar } \\
(\mathbf{p p m})\end{array}$ & Absorbansi \\
\hline 1 & Blanko & 0,0000 \\
2 & 15 & 0,0284 \\
3 & 20 & 0,0398 \\
4 & 22 & 0,0487 \\
5 & 25 & 0,0552 \\
6 & 30 & 0,0653 \\
\hline
\end{tabular}

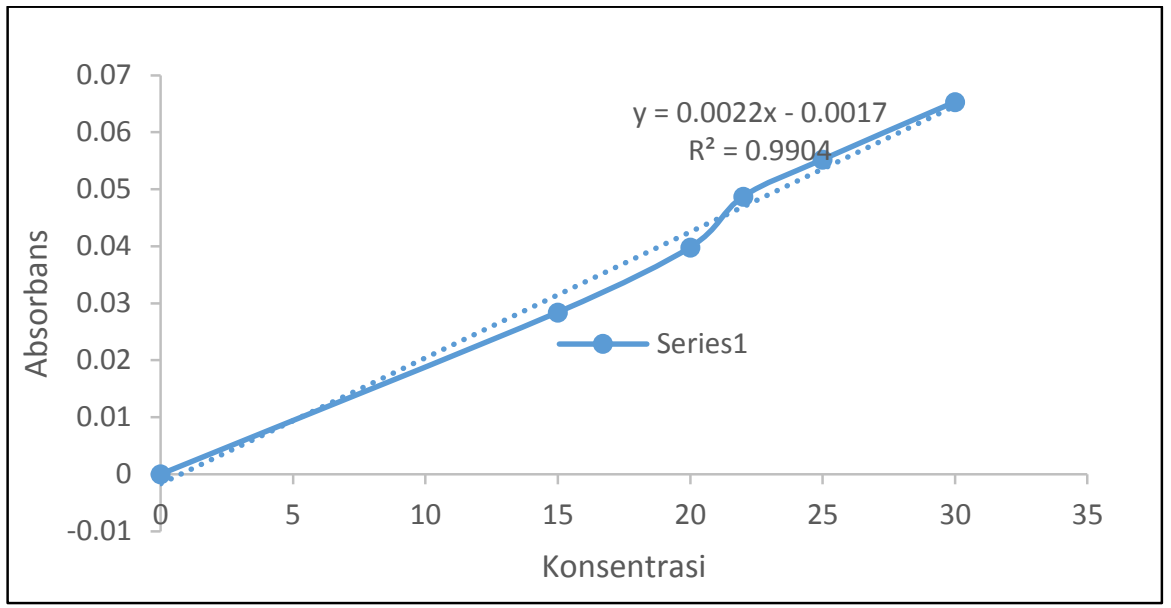

Gambar 1. Grafik Hubungan antara Konsentrasi dengan Absorbansi

Tabel 2. Data Hasil Absorbansi Larutan Sampel Kecap Secara Spektrofotometer UV-Vis

Keterangan :

\begin{tabular}{ccc}
\hline No & Sampel & Absorbansi \\
\hline 1 & Kecap 1 & 0,0218 \\
2 & Kecap 2 & 0,0283 \\
3 & Kecap 3 & 0,0224 \\
4 & Kecap 4 & 0,0387 \\
5 & Kecap 5 & 0,0160 \\
6 & Kecap 6 & 0,0206 \\
7 & Kecap 7 & 0,0251 \\
8 & Kecap 8 & 0,0143 \\
9 & Kecap 9 & 0,0321 \\
10 & Kecap 10 & 0,0146 \\
\hline
\end{tabular}

1-5 = kecap mie instan

6-10 = kecap botolan 
Tabel 3. Data Hasil Perhitungan Kadar Nipagin Pada Kecap Mie Instan dan Kecap Botolan Secara Spektrofotometer UV-Vis

\begin{tabular}{clcc}
\hline No & Sampel & \multicolumn{2}{c}{ Kadar $(\mathbf{m g} / \mathbf{g})$} \\
\cline { 3 - 4 } & & $\begin{array}{c}\text { Kecap Mie } \\
\text { Instan }\end{array}$ & Kecap Botolan \\
\hline 1 & Kecap 1 & 0,0105 & - \\
2 & Kecap 2 & 0,0135 & - \\
3 & Kecap 3 & 0,0108 & - \\
4 & Kecap 4 & 0,0120 & - \\
5 & Kecap 5 & 0,0073 & - \\
6 & Kecap 6 & - & 0,0182 \\
7 & Kecap 7 & - & 0,0079 \\
8 & Kecap 8 & - & 0,0100 \\
9 & Kecap 9 & - & 0,0071 \\
10 & Kecap 10 & - & 0,0582 \\
\hline
\end{tabular}

